\title{
High-quality permanent draft genome sequence of the Parapiptadenia rigida-nodulating Burkholderia sp. strain UYPR1.413
}

Sofie E. De Meyer ${ }^{1}$, Elena Fabiano ${ }^{2}$, Rui Tian ${ }^{1}$, Peter Van Berkum ${ }^{3}$, Rekha Seshadri ${ }^{4}$, TBK Reddy ${ }^{4}$, Victor Markowitz ${ }^{5}$, Natalia Ivanova ${ }^{4}$, Amrita Pati $^{4}$, Tanja Woyke ${ }^{4}$, John Howieson ${ }^{1}$, Nikos Kyrpides $^{4,6}$ and Wayne Reeve ${ }^{1 *}$

\begin{abstract}
Burkholderia sp. strain UYPR1.413 is an aerobic, motile, Gram-negative, non-spore-forming rod that was isolated from a root nodule of Parapiptadenia rigida collected at the Angico plantation, Mandiyu, Uruguay, in December 2006. A survey of symbionts of $P$. rigida in Uruguay demonstrated that this species is nodulated predominantly by Burkholderia microsymbionts. Moreover, Burkholderia sp. strain UYPR1.413 is a highly efficient nitrogen fixing symbiont with this host. Currently, the only other sequenced isolate to fix with this host is Cupriavidus sp. UYPR2.512. Therefore, Burkholderia sp. strain UYPR1.413 was selected for sequencing on the basis of its environmental and agricultural relevance to issues in global carbon cycling, alternative energy production, and biogeochemical importance, and is part of the GEBA-RNB project. Here we describe the features of Burkholderia sp. strain UYPR1.413, together with sequence and annotation. The 10,373,764 bp high-quality permanent draft genome is arranged in 336 scaffolds of 342 contigs, contains 9759 protein-coding genes and 77 RNA-only encoding genes.
\end{abstract}

Keywords: Root-nodule bacteria, Nitrogen fixation, Rhizobia, Betaproteobacteria, GEBA-RNB

\section{Introduction}

Rhizobia are soil bacteria that have acquired the ability to establish symbiotic associations with plants, mainly from the Fabaceae family, and carry out the Biological Nitrogen Fixation (BNF) process. BNF is catalyzed by the rhizobial nitrogenase complex, whereby $\mathrm{N}_{2}$ is reduced to ammonium.

Well-known and studied rhizobia are those belonging to the $\alpha$-proteobacteria (eg. Azorhizobium, Bradyrhizobium, Ensifer, Mesorhizobium and Rhizobium). In 2001 symbiotic nitrogen fixing bacteria belonging to the group of Betaproteobacteria were reported as root nodule bacteria, introducing the term of Alpha and Beta-rhizobia to differentiate both groups of rhizobia $[1,2]$. The Beta-rhizobia identified so far belong to only two genera: Burkholderia and Cupriavidus and the association seem to be mainly with plants from the Mimosoideae subfamily [3]. Additionally, studies indicate that the South American Mimosa genus is preferentially nodulated by Beta-rhizobia [4]. Different

\footnotetext{
* Correspondence: W.Reeve@murdoch.edu.au

'Centre for Rhizobium Studies, Murdoch University, Murdoch, WA, Australia Full list of author information is available at the end of the article
}

Beta-rhizobia species have been described belonging to the Burkholderia genus (eg. B. caballeronis, B. caribensis, B. diazotrophica, B. dilworthii, B. mimosarum, B. nodosa, B. phymatum, B. rhynchosiae, B. sabiae, B. sprentiae, B. symbiotica and B. tuberum) but only two in the Cupriavidus genus (C. taiwanensis and C. necator) [2, 5-17].

Burkholderia sp. UYPR1.413 strain has been isolated from a root nodule of Parapiptadenia rigida (Benth.) Brenan found in an angico plantation in Artigas, Uruguay [18]. P. rigida belongs to the Mimosoideae subfamily and is a woody species, which can reach $30 \mathrm{~m}$ in height and a diameter of 60 to $80 \mathrm{~cm}$ [19]. The wood is of excellent quality, heavy, elastic, very hard and quite durable, rich in tannins and has medicinal properties [20]. There are six different species of Parapiptadenia in the Americas of which only $P$. rigida is present in Uruguay. A survey of symbionts of $P$. rigida in Uruguay demonstrated that this species is nodulated by rhizobia belonging to the genera Burkholderia, Cupriavidus and Rhizobium, of which the Burkholderia microsymbionts predominated [18]. Burkholderia sp. UYPR1.413 strain belongs to a group of microsymbionts that were able to 


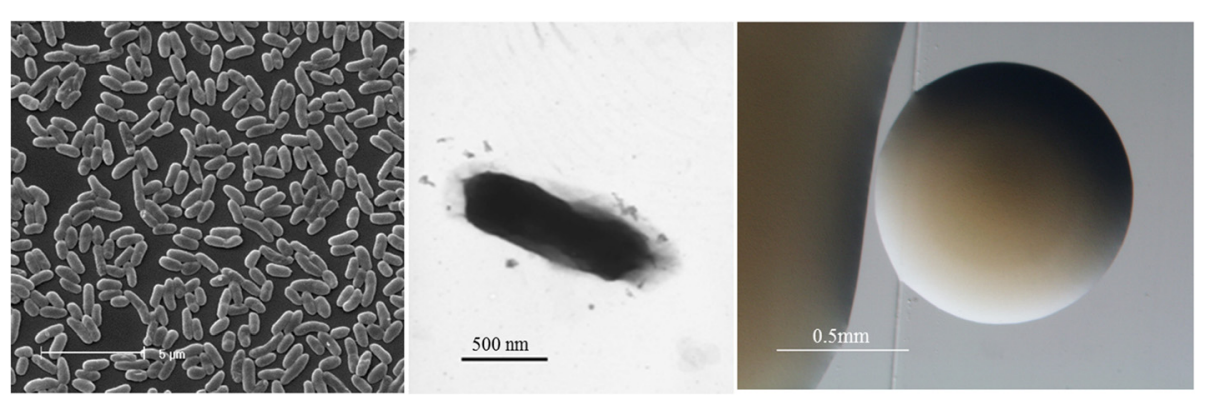

Fig. 1 Images of Burkholderia sp. strain UYPR1.413 using scanning (Left) and transmission (Center) electron microscopy and the appearance of colony morphology on solid media (Right)

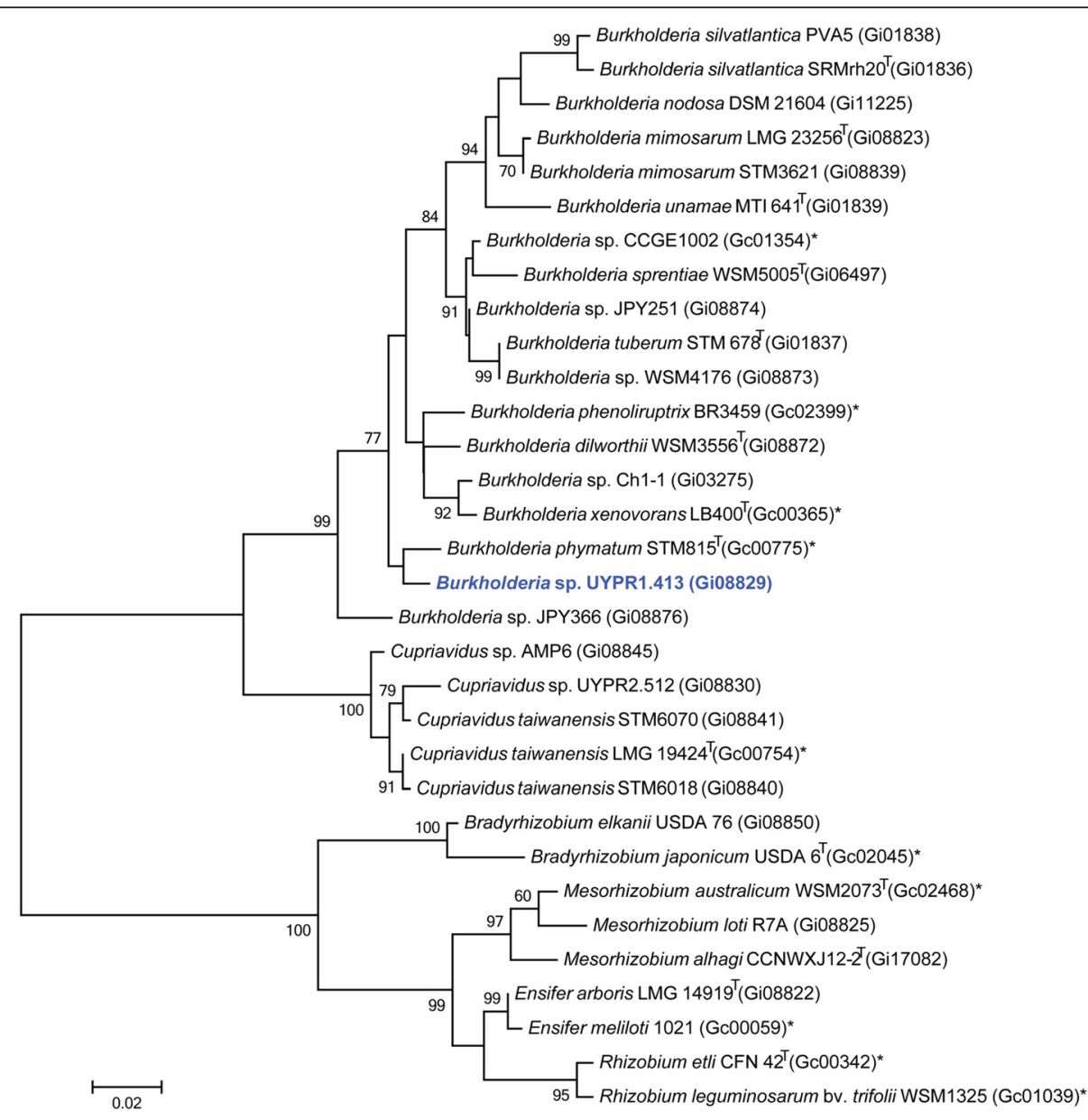

Fig. 2 Phylogenetic tree highlighting the position of Burkholderia sp. strain UYPR1.413 (shown in blue print) relative to other type and non-type strains in the Burkholderia genus using 1046 bp internal region of the 165 rRNA gene. Several Alpha-rhizobia sequences were used as outgroup. All sites were informative and there were no gap-containing sites. Phylogenetic analyses were performed using MEGA, version 5.05 [47]. The tree was built using the maximum likelihood method with the General Time Reversible model. Bootstrap analysis with 500 replicates was performed to assess the support of the clusters. Type strains are indicated with a superscript T. Strains with a genome sequencing project registered in GOLD [30] have the GOLD ID provided after the strain number. Finished genomes are designated with an asterisk 
nodulate and fix nitrogen with $P$. rigida [18]. In this work we present the description of the Burkholderia sp. UYPR1.413 high-quality permanent draft genome sequence and its annotation.

\section{Organism information}

\section{Classification and features}

Burkholderia sp. strain UYPR1.413 is a motile, Gramnegative, non-spore-forming rod (Fig. 1 Left, Center) in the order Burkholderiales of the class Betaproteobacteria. The rod-shaped form varies in size with dimensions of 0.3$0.5 \mu \mathrm{m}$ in width and $1.0-2.0 \mu \mathrm{m}$ in length (Fig. 1 Left). It is fast growing, forming $0.5-1 \mathrm{~mm}$ diameter colonies after $24 \mathrm{~h}$ when grown on TY [21] at $28^{\circ} \mathrm{C}$. Colonies on TY are white-opaque, slightly domed, moderately mucoid with smooth margins (Fig. 1 Right).
Figure 2 shows the phylogenetic relationship of Burkholderia sp. strain UYPR1.413 in a 16S rRNA gene sequence based tree. This strain is phylogenetically most related to Burkholderia sabiae $\mathrm{Br} 3407^{\mathrm{T}}$, Burkholderia caribensis MWAP64 ${ }^{\mathrm{T}}$ and Burkholderia phymatum STM815 ${ }^{\mathrm{T}}$ with sequence identities to UYPR1.413 16S rRNA gene sequence of $98.96,98.64$ and $98.56 \%$, respectively, as determined using the EzTaxon-e server [22]. Burkholderia sabiae $\mathrm{Br} 3407^{\mathrm{T}}$ was first isolated from root nodules of $\mathrm{Mi}$ mosa caesalpiniifolia, a native tree to Brazil [6]. Burkholderia caribensis MWAP64 ${ }^{\mathrm{T}}$ was first isolated from vertisol in Martinique [5] and related strains have been identified as a plant growth promoting bacteria for grain Amaranth and Mango trees [23, 24] and nitrogen fixing root nodule bacteria for several Mimosa species [25, 26]. Burkholderia phymatum STM $815^{\mathrm{T}}$ is also known to nodulate effectively with several Mimosa species [27]. Minimum Information

Table 1 Classification and general features of Burkholderia sp. strain UYPR1.413 in accordance with the MIGS recommendations [28] published by the Genome Standards Consortium [48]

\begin{tabular}{|c|c|c|c|}
\hline MIGS ID & Property & Term & Evidence code \\
\hline & Classification & Domain Bacteria & TAS [49] \\
\hline & & Phylum Proteobacteria & $\operatorname{TAS}[50,51]$ \\
\hline & & Class Betaproteobacteria & TAS [52] \\
\hline & & Order Burkholderiales & TAS [53] \\
\hline & & Family Burkholderiaceae & TAS [54] \\
\hline & & Genus Burkholderia & TAS [55] \\
\hline & & Species Burkholderia sp. & IDA \\
\hline & & (Type) strain UYPR1.413 & IDA \\
\hline & Gram stain & Negative & TAS [55] \\
\hline & Cell shape & Rod & IDA \\
\hline & Motility & Motile & IDA \\
\hline & Sporulation & non-sporulating & TAS [55] \\
\hline & Temperature range & Not reported & \\
\hline & Optimum temperature & $28^{\circ} \mathrm{C}$ & IDA \\
\hline & pH range; Optimum & Not reported & \\
\hline & Carbon source & Not reported & \\
\hline MIGS-6 & Habitat & Soil, root nodule on host & TAS [18] \\
\hline MIGS-6.3 & Salinity & Not reported & \\
\hline MIGS-22 & Oxygen requirement & Aerobic & IDA \\
\hline MIGS-15 & Biotic relationship & Symbiotic & TAS [18] \\
\hline MIGS-14 & Pathogenicity & Non-pathogenic & NAS \\
\hline MIGS-4 & Geographic location & Uruguay & TAS [18] \\
\hline MIGS-5 & Sample collection & December, 2006 & TAS [18] \\
\hline MIGS-4.1 & Latitude & -30.507 & TAS [18] \\
\hline MIGS-4.2 & Longitude & -57.702 & TAS [18] \\
\hline MIGS-4.4 & Altitude & $76 \mathrm{~m}$ & IDA \\
\hline
\end{tabular}

Evidence codes-IDA: Inferred from Direct Assay; TAS: Traceable Author Statement (i.e., a direct report exists in the literature); NAS: Non-traceable Author Statement (i.e., not directly observed for the living, isolated sample, but based on a generally accepted property for the species, or anecdotal evidence). These evidence codes are from the Gene Ontology project [56] 
Table 2 Genome sequencing project information for Burkholderia sp. strain UYPR1.413

\begin{tabular}{lll}
\hline MIGS ID & Property & Term \\
\hline MIGS-31 & Finishing quality & Permanent-draft \\
MIGS-28 & Libraries used & Illumina Std PE \\
MIGS-29 & Sequencing platforms & Illumina HiSeq 2000 \\
MIGS-31.2 & Fold coverage & $117.1 \times$ Illumina \\
MIGS-30 & Assemblers & Velvet version 1.1.04, ALLPATHS-LG V.r41043 \\
MIGS-32 & Gene calling methods & Prodigal 1.4 \\
& Locus Tag & A3A7 \\
& Genbank ID & JAFD01000000 \\
& Genbank Date of Release & January 23, 2014 \\
& GOLD ID & Gp0010091 \\
& BIOPROJECT & PRJNA165303 \\
MIGS-13 & Source Material Identifier & UYPR1.413 \\
& Project relevance & Symbiotic N $\mathrm{N}_{2}$ fixation, agriculture \\
\hline
\end{tabular}

about the Genome Sequence (MIGS) [28] is provided in Table 1.

\section{Symbiotaxonomy}

Burkholderia sp. strain UYPR1.413 was isolated from Parapiptadenia rigida, a Mimosoideae legume native to Uruguay [18]. This tree is native to South America, including south Brazil, Argentina, Paraguay, and Uruguay, and used by locals for timber and as a source of gums, tannins and essential oils [18]. Burkholderia sp. strain UYPR1.413 is able to renodulate its original host and is highly efficient in fixing nitrogen with this host [18]. A selection of host plants, including Trifolium repens, Medicago sativa, Peltophorum dubium and Mimosa pudica were investigated previously for their ability to nodulate with UYPR1.413 and only $M$. pudica plants were nodulated by UYPR1.413, albeit ineffectively [18].

\section{Genome sequencing information Genome project history}

This organism was selected for sequencing on the basis of its environmental and agricultural relevance to issues in global carbon cycling, alternative energy production, and biogeochemical importance, and is part of the Genomic Encyclopedia of Bacteria and Archaea, The Root Nodulating Bacteria chapter (GEBA-RNB) project at the U.S. Department of Energy, Joint Genome Institute (JGI) for projects of relevance to agency missions [29]. The genome project is deposited in the Genomes OnLine Database [30] and the high-quality permanent draft genome sequence in IMG [31]. Sequencing, finishing and annotation were performed by the JGI using state of the art sequencing technology [32]. A summary of the project information is shown in Table 2.

\section{Growth conditions and genomic DNA preparation}

Burkholderia sp. strain UYPR1.413 was grown to mid logarithmic phase in TY rich media [21] on a gyratory shaker at $28{ }^{\circ} \mathrm{C}$. DNA was isolated from $60 \mathrm{~mL}$ of cells using a CTAB (Cetyl trimethyl ammonium bromide) bacterial genomic DNA isolation method [33].

\section{Genome sequencing and assembly}

The draft genome of Burkholderia sp. UYPR1.413 was generated at the DOE Joint genome Institute (JGI) using state of the art technology [32]. An Illumina Std shotgun library was constructed and sequenced using the Illumina HiSeq 2000 platform which generated 23,255,298 reads totaling $3488.3 \mathrm{Mbp}$. All general aspects of library

Table 3 Genome statistics for Burkholderia sp. strain UYPR1.413

\begin{tabular}{lll}
\hline Attribute & Value & \% of total \\
\hline Genome size (bp) & $10,373,764$ & 100 \\
DNA coding (bp) & $8,806,315$ & 84.89 \\
DNA G + C (bp) & $6,461,024$ & 62.28 \\
DNA scaffolds & 336 & \\
Total genes & 9836 & 100 \\
Protein-coding genes & 9759 & 99.22 \\
RNA genes & 77 & 0.78 \\
Pseudo genes & 1 & 0.01 \\
Genes in internal clusters & 471 & 4.79 \\
Genes with function prediction & 7467 & 75.92 \\
Genes assigned to COGs & 6103 & 62.05 \\
Genes with Pfam domains & 7650 & 77.78 \\
Genes with signal peptides & 934 & 9.50 \\
Genes with transmembrane helices & 2097 & 21.32 \\
CRISPR repeats & 1 & \\
\hline
\end{tabular}


construction and sequencing performed at the JGI can be found at the JGI web site [34]. All raw Illumina sequence data was passed through DUK, a filtering program developed at JGI, which removes known Illumina sequencing and library preparation artifacts (Mingkun L, Copeland A, Han J. unpublished). The following steps were then performed for assembly: (1) filtered Illumina reads were assembled using Velvet version 1.1.04 [35] (2) 1-3 Kbp simulated paired end reads were created from
Velvet contigs using wgsim [36] (3) Illumina reads were assembled with simulated read pairs using Allpaths-LG (version r41043) [37]. Parameters for assembly steps were: 1 ) Velvet (velveth: 63 -shortPaired and velvetg: -very clean yes -exportFiltered yes -min contig lgth 500 -scaffolding no -cov cutoff 10) 2) wgsim (-e $0-1 \quad 100-2$ 100 -r 0 -R 0 -X 0) 3) Allpaths-LG (PrepareAllpathsInputs: PHRED $64=1$ PLOIDY $=1$ FRAG COVERAGE $=$ 125 JUMP COVERAGE $=25$ LONG JUMP COV $=50$,

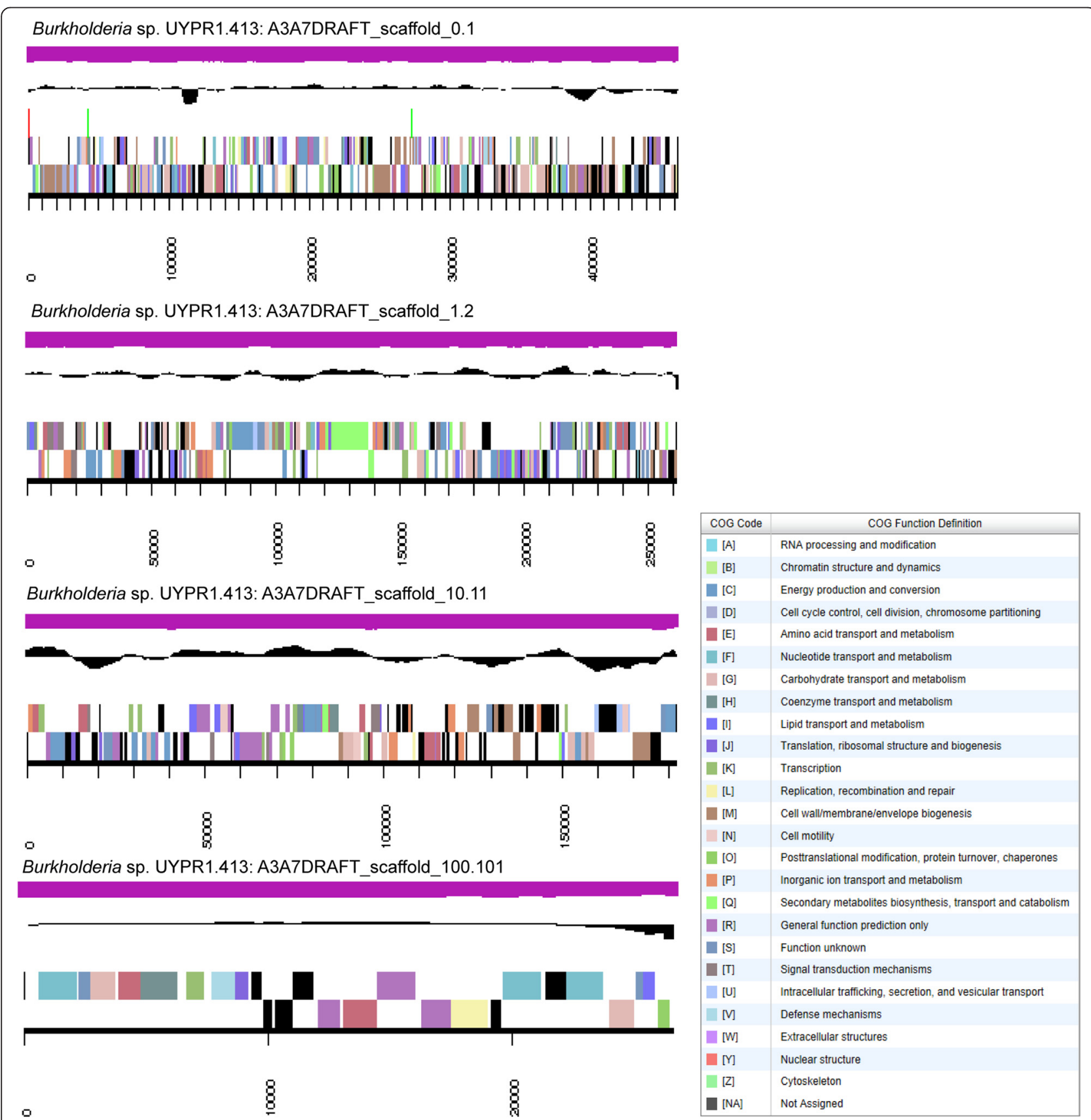

Fig. 3 Graphical map of the four largest scaffolds of the genome of Burkholderia sp. strain UYPR1.413. From the bottom to the top of each scaffold: Genes on forward strand (color by COG categories as denoted by the IMG platform), Genes on reverse strand (color by COG categories), RNA genes (tRNAs green, sRNAs red, other RNAs black), GC content, GC skew 
RunAllpathsLG: $\quad$ THREADS $=8 \quad$ RUN $=$ std $\quad$ shredpairs TARGETS $=$ standard VAPI WARN ONLY $=$ True OVERWRITE $=$ True). The final draft assembly contained 342 contigs in 336 scaffolds. The total size of the genome is 10.4 Mbp and the final assembly is based on 1214.2 Mbp of Illumina data, which provides an average of $117.1 \times$ coverage of the genome.

\section{Genome annotation}

Genes were identified using Prodigal [38], as part of the DOE-JGI genome annotation pipeline [39, 40] followed by a round of manual curation using GenePRIMP [41] for finished genomes and Draft genomes in fewer than 10 scaffolds. The predicted CDSs were translated and used to search the National Center for Biotechnology Information (NCBI) non-redundant database, UniProt, TIGRFam, Pfam, KEGG, COG, and InterPro databases. The tRNAScanSE tool [42] was used to find tRNA genes, whereas ribosomal RNA genes were found by searches against models of the ribosomal RNA genes built from SILVA [43]. Other non-coding RNAs such as the RNA components of the protein secretion complex and the RNase P were identified by searching the genome for the corresponding Rfam profiles using INFERNAL [44]. Additional gene prediction analysis and manual functional annotation was performed within the Integrated Microbial Genomes-Expert Review (IMG-ER) system [45] developed by the Joint Genome Institute, Walnut Creek, CA, USA.

\section{Genome properties}

The genome is 10,373,764 nucleotides with $62.28 \%$ GC content (Table 3) and comprised of 336 scaffolds and 342 contigs (Fig. 3). From a total of 9836 genes, 9759 were protein encoding and 77 RNA only encoding genes. The majority of genes $(75.92 \%)$ were assigned a putative function whilst the remaining genes were annotated as hypothetical. The distribution of genes into COGs functional categories is presented in Table 4.

\section{Conclusion}

Burkholderia sp. UYPR1.413 belongs to a group of Beta-rhizobia isolated from Parapiptadenia rigida, a native tree from Uruguay belonging to the Mimosoideae

Table 4 Number of protein coding genes of Burkholderia sp. strain UYPR1.413 associated with the general COG functional categories

\begin{tabular}{|c|c|c|c|}
\hline Code & Value & $\%$ Age & COG Category \\
\hline J & 193 & 2.79 & Translation, ribosomal structure and biogenesis \\
\hline A & 1 & 0.01 & RNA processing and modification \\
\hline K & 721 & 10.42 & Transcription \\
\hline L & 231 & 3.34 & Replication, recombination and repair \\
\hline B & 4 & 0.06 & Chromatin structure and dynamics \\
\hline D & 36 & 0.52 & Cell cycle control, Cell division, chromosome partitioning \\
\hline V & 67 & 0.97 & Defense mechanisms \\
\hline $\mathrm{T}$ & 332 & 4.80 & Signal transduction mechanisms \\
\hline M & 405 & 5.85 & Cell wall/membrane/envelope biogenesis \\
\hline N & 136 & 1.96 & Cell motility \\
\hline$U$ & 200 & 2.89 & Intracellular trafficking, secretion, and vesicular transport \\
\hline O & 196 & 2.83 & Posttranslational modification, protein turnover, chaperones \\
\hline C & 526 & 7.60 & Energy production and conversion \\
\hline G & 527 & 7.61 & Carbohydrate transport and metabolism \\
\hline E & 789 & 11.40 & Amino acid transport and metabolism \\
\hline $\mathrm{F}$ & 103 & 1.49 & Nucleotide transport and metabolism \\
\hline H & 220 & 3.18 & Coenzyme transport and metabolism \\
\hline । & 325 & 4.70 & Lipid transport and metabolism \\
\hline P & 308 & 4.45 & Inorganic ion transport and metabolism \\
\hline Q & 248 & 3.58 & Secondary metabolite biosynthesis, transport and catabolism \\
\hline $\mathrm{R}$ & 794 & 11.47 & General function prediction only \\
\hline S & 559 & 8.08 & Function unknown \\
\hline- & 3733 & 37.95 & Not in COGS \\
\hline
\end{tabular}


legume group [18]. This tree is also native to the south of Brazil, Argentina and Paraguay [18]. Phylogenetic analysis revealed that UYPR1.413 is most closely related to Burkholderia sabiae $\mathrm{Br} 3407^{\mathrm{T}}$, Burkholderia caribensis MWAP64 ${ }^{\mathrm{T}}$ and Burkholderia phymatum STM815 ${ }^{\mathrm{T}}$. Interestingly, $\mathrm{Br} 3407^{\mathrm{T}}$ was isolated from nitrogenfixing nodules on the roots of Mimosa caesalpiniifolia, a legume tree native to Brazil [6]. MWAP64 ${ }^{\mathrm{T}}$ has not been reported to nodulate legume plants, however $B$. caribensis TJ182 is able to nodulate and fix nitrogen with Mimosa pigra [7]. STM $815^{\mathrm{T}}$ was originally isolated from Macroptilium atropurpureum but could not be authenticated on this host [1]. Additional studies showed that STM815 ${ }^{\mathrm{T}}$ is instead able to nodulate a wide range of Mimosa species [27]. Glasshouse experiments from previous studies have shown that Burkholderia sp. UYPR1.413 is also able to nodulate Mimosa pudica seedlings, albeit ineffectively [18]. However, it is different from the other microsymbiont in that it can form an effective association with Parapiptadenia rigida. The only other sequenced isolate to fix with this host is Cupriavidus sp. UYPR2.512 [46]. There are in total 13 Burkholderia strains that are known legume symbionts; four (WSM3556 ${ }^{\mathrm{T}}$, WSM4176, WSM5005 ${ }^{\mathrm{T}}$, STM $678^{\mathrm{T}}$ ) nodulate South African papilionoid species, in contrast to the other nine (BR3459, CCGE1002, DSM 21604, JPY251, JPY366, LMG 23256 ${ }^{\mathrm{T}}$, STM815, STM3621 and UYPR1.413) that are able to nodulate mimosoid species. A comparison of the mimosoid nodulating strains reveals that UYPR1.413 has the largest genome (10.4 Mbp), with the highest KOG count (1670) and the lowest GC (65.28\%) percentage in this group. All 13 of these genomes share the nitrogenaseRXN MetaCyc pathway catalyzed by a multiprotein nitrogenase complex. However, only Burkholderia sp. UYPR1.413 has been shown to fix effectively with Parapiptadenia rigida. The genome attributes of Burkholderia sp. UYPR1.413 will therefore be important for ongoing molecular analysis of the plant microbe interactions required for the establishment of leguminous tree symbioses with this host.

\section{Abbreviations}

GEBA-RNB: Genomic Encyclopedia of Bacteria and Archaea-Root Nodule Bacteria; JGl: Joint Genome Institute; TY: Trypton Yeast; CTAB: Cetyl trimethyl ammonium bromide; WSM: Western Australian Soil Microbiology; BNF: Biological Nitrogen Fixation.

\section{Competing interests}

The authors declare that they have no competing interests.

\section{Authors' contributions}

EF supplied the strain and background information for this project, PVB supplied DNA to JGI, TR performed all imaging, SDM and WR drafted the paper, JH provided financial support and all other authors were involved in sequencing the genome and editing the final manuscript. All authors read and approved the final manuscript.

\section{Acknowledgements}

This work was performed under the auspices of the US Department of Energy's Office of Science, Biological and Environmental Research Program, and by the University of California, Lawrence Berkeley National Laboratory under contract No. DE-AC02-05CH11231, Lawrence Livermore National Laboratory under Contract No. DE-AC52-07NA27344, and Los Alamos National Laboratory under contract No. DE-AC02-06NA25396.

\section{Author details}

${ }^{1}$ Centre for Rhizobium Studies, Murdoch University, Murdoch, WA, Australia. ${ }^{2}$ Instituto de Investigaciones Biológicas Clemente Estable, Montevideo, Uruguay. ${ }^{3}$ Soybean Genomics and improvement laboratory Bldg 006, BARC-West USDA ARS, 10300 Baltimore Blvd, Beltsville, MD 20705, USA. ${ }^{4}$ DOE Joint Genome Institute, Walnut Creek, CA, USA. ${ }^{5}$ Biological Data Management and Technology Center, Lawrence Berkeley National Laboratory, Berkeley, CA, USA. ${ }^{6}$ Department of Biological Sciences, King Abdulaziz University, Jeddah, Saudi Arabia.

Received: 19 November 2014 Accepted: 13 May 2015

Published online: 04 June 2015

\section{References}

1. Moulin L, Munive A, Dreyfus B, Boivin-Masson C. Nodulation of legumes by members of the beta-subclass of Proteobacteria. Nature. 2001;411:948-50.

2. Chen WM, Laevens S, Lee TM, Coenye T, De Vos P, Mergeay M, et al. Ralstonia taiwanensis sp. nov., isolated from root nodules of Mimosa species and sputum of a cystic fibrosis patient. Int J Syst Evol Microbiol. 2001;51:1729-35.

3. Gyaneshwar P, Hirsch AM, Moulin L, Chen WM, Elliott GN, Bontemps C, et al. Legume-nodulating betaproteobacteria: diversity, host range, and future prospects. Mol Plant Microbe Interact. 2011;24:1276-88.

4. dos Reis Jr FB, Simon MF, Gross E, Boddey RM, Elliott GN, Neto NE, et al. Nodulation and nitrogen fixation by Mimosa spp. in the Cerrado and Caatinga biomes of Brazil. New Phytol. 2010;186:934-46.

5. Achouak W, Christen R, Barakat M, Martel MH, Heulin T. Burkholderia caribensis sp. nov., an exopolysaccharide-producing bacterium isolated from vertisol microaggregates in Martinique. Int J Syst Bacteriol. 1999;49:787-94.

6. Chen WM, de Faria SM, Chou J, James EK, Elliott GN, Sprent Jl, et al. Burkholderia sabiae sp. nov., isolated from root nodules of Mimosa caesalpiniifolia. Int J Syst Evol Microbiol. 2008;58:2174-9.

7. Chen WM, James EK, Chou JH, Sheu SY, Yang SZ, Sprent JI. Beta-rhizobia from Mimosa pigra, a newly discovered invasive plant in Taiwan. New Phytol. 2005;168:661-75.

8. De Meyer SE, Cnockaert M, Ardley JK, Van Wyk B-E, Vandamme PA, Howieson JG. Burkholderia dilworthii sp. nov., isolated from Lebeckia ambigua root nodules. Int J Syst Evol Microbiol. 2014;64:1090-5.

9. Martinez-Aguilar L, Salazar-Salazar C, Mendez R, Caballero-Mellado J, Hirsch AM, Vasquez-Murrieta MS, et al. Burkholderia caballeronis sp nov., a nitrogen fixing species isolated from tomato (Lycopersicon esculentum) with the ability to effectively nodulate Phaseolus vulgaris. Antonie Leeuwenhoek. 2013;104:1063-71.

10. Sheu S-Y, Chou J-H, Bontemps C, Elliott GN, Gross E, dos Reis Junior FB, et al. Burkholderia diazotrophica sp. nov., isolated from root nodules of Mimosa spp. Int J Syst Evol Microbiol. 2013;63:435-441.

11. Sheu S-Y, Chou J-H, Bontemps C, Elliott GN, Gross E, James EK, et al. Burkholderia symbiotica sp. nov., isolated from root nodules of Mimosa spp. native to north-east Brazil. Int J Syst Evol Microbiol. 2012;62:2272-8.

12. Chen WM, de Faria SM, James EK, Elliott GN, Lin KY, Chou JH, et al. Burkholderia nodosa sp nov., isolated from root nodules of the woody Brazilian legumes Mimosa bimucronata and Mimosa scabrella. Int J Syst Evol Microbiol. 2007;57:1055-9.

13. Chen WM, James EK, Coenye T, Chou JH, Barrios E, de Faria SM, et al. Burkholderia mimosarum sp nov., isolated from root nodules of Mimosa spp. from Taiwan and South America. Int J Syst Evol Microbiol. 2006;56:1847-51.

14. De Meyer SE, Cnockaert M, Ardley JK, Maker G, Yates R, Howieson JG, et al. Burkholderia sprentiae sp. nov., isolated from Lebeckia ambigua root nodules. Int J Syst Evol Microbiol. 2013;63:3950-7.

15. De Meyer SE, Cnockaert M, Ardley JK, Trengove RD, Garau G, Howieson JG, et al. Burkholderia rhynchosiae sp. nov., isolated from Rhynchosia ferulifolia root nodules. Int J Syst Evol Microbiol. 2013;63:3944-9. 
16. Vandamme $\mathrm{P}$, Coenye $\mathrm{T}$. Taxonomy of the genus Cupriavidus: a tale of lost and found. Int J Syst Evol Microbiol. 2004;54:2285-9.

17. Vandamme P, Goris J, Chen WM, de Vos P, Willems A. Burkholderia tuberum sp. nov. and Burkholderia phymatum sp. nov., nodulate the roots of tropical legumes. Syst Appl Microbiol. 2002;25:507-12.

18. Taule C, Zabaleta M, Mareque C, Platero R, Sanjurjo L, Sicardi M, et al. New betaproteobacterial rhizobium strains able to efficiently nodulate Parapiptadenia rigida (Benth.) Brenan. Appl Environ Microbiol. 2012;78:1692-700

19. Jobson RW, Luckow M. Phylogenetic study of the genus Piptadenia (Mimosoideae : Leguminosae) using plastid trnL-F and trnK/matK sequence data. Syst Bot. 2007:32:569-75.

20. Izaguirre P, Beyhaut R. Las leguminosas en Uruguay y regiones vecinas. Uruguay: Agropecuaria Hemisferio Sur; 2003.

21. Beringer JE. R factor transfer in Rhizobium leguminosarum. J Gen Microbiol. 1974;84:188-98.

22. Kim O-S, Cho Y-J, Lee K, Yoon S-H, Kim M, Na H, et al. Introducing EzTaxon-e: a prokaryotic $16 \mathrm{~S}$ rRNA gene sequence database with phylotypes that represent uncultured species. Int J Syst Evol Microbiol. 2012;62:716-21.

23. de los Santos-Villalobos S, de Folter S, Delano-Frier JP, Gomez-Lim MA, Guzman-Ortiz DA, Pena-Cabriales JJ. Growth promotion and flowering induction in mango (Mangifera indica L. CV "Ataulfo") trees by Burkholderia and Rhizobium Inoculation: morphometric, biochemical, and molecular events. J Plant Growth Regul. 2013;32:615-27.

24. Parra-Cota Fl, Pena-Cabriales JJ, de los Santos-Villalobos S, MartinezGallardo NA, Delano-Frier JP. Burkholderia ambifaria and B. caribensis promote growth and increase yield in grain amaranth (Amaranthus cruentus and $A$. hypochondriacus) by improving plant nitrogen uptake. PLoS One. 2014:9:14.

25. Chen W, de Faria SM, Straliotto R, Pitard RM, Simões-Araùjo JL, Chou J, et al. Proof that Burkholderia strains form effective symbioses with legumes: a study of novel Mimosa-nodulating strains from South America. Appl Environ Microbiol. 2005;71:7461-71.

26. Chen WM, Moulin L, Bontemps C, Vandamme P, Bena G, Boivin-Masson C. Legume symbiotic nitrogen fixation by beta-proteobacteria is widespread in nature. J Bacteriol. 2003;185:7266-72.

27. Elliott GN, Chen WM, Chou JH, Wang HC, Sheu SY, Perin L, et al. Burkholderia phymatum is a highly effective nitrogen-fixing symbiont of Mimosa spp. and fixes nitrogen ex planta. New Phytol. 2007;173:168-80.

28. Field D, Garrity G, Gray T, Morrison N, Selengut J, Sterk P, et al. Towards a richer description of our complete collection of genomes and metagenomes "Minimum Information about a Genome Sequence" (MIGS) specification. Nat Biotechnol. 2008;26:541-7.

29. Reeve W, Ardley J, Tian R, Eshraghi L, Yoon J, Ngamwisetkun P, et al. A genomic encyclopedia of the root nodule bacteria: assessing genetic diversity through a systematic biogeographic survey. Stand Genomic Sci. 2015;10:14.

30. Pagani I, Liolios K, Jansson J, Chen IM, Smirnova T, Nosrat B, et al. The Genomes OnLine Database (GOLD) v. 4: status of genomic and metagenomic projects and their associated metadata. Nucleic Acids Res. 2012;40:D571-9.

31. Markowitz VM, Chen I-MA, Palaniappan K, Chu K, Szeto E, Pillay M, et al. IMG 4 version of the integrated microbial genomes comparative analysis system. Nucleic Acids Res. 2014;42:D560-7.

32. Mavromatis K, Land ML, Brettin TS, Quest DJ, Copeland A, Clum A, et al. The fast changing landscape of sequencing technologies and their impact on microbial genome assemblies and annotation. PLoS One. 2012;7, e48837.

33. CTAB DNA extraction protocol. [http://jgi.doe.gov/collaborate-with-jgi/pmooverview/protocols-sample-preparation-information/].

34. JGI Website. [http://www.jgi.doe.gov].

35. Zerbino D, Birney E. Velvet: algorithms for de novo short read assembly using de Bruijn graphs. Genome Res. 2008;18:821-9.

36. wgsim. [https://github.com/lh3/wgsim].

37. Gnerre S, MacCallum I, Przybylski D, Ribeiro FJ, Burton JN, Walker BJ, et al. High-quality draft assemblies of mammalian genomes from massively parallel sequence data. Proc Natl Acad Sci U S A. 2011;108:1513-8.

38. Hyatt D, Chen GL, Locascio PF, Land ML, Larimer FW, Hauser L. Prodigal: prokaryotic gene recognition and translation initiation site identification. BMC Bioinformatics. 2010;11:119.
39. Chen IM, Markowitz VM, Chu K, Anderson I, Mavromatis K, Kyrpides NC, et al. Improving microbial genome annotations in an integrated database context. PLoS One. 2013;8, e54859.

40. Mavromatis K, Ivanova NN, Chen IM, Szeto E, Markowitz VM, Kyrpides NC. The DOE-JGl standard operating procedure for the annotations of microbial genomes. Stand Genomic Sci. 2009;1:63-7.

41. Pati A, Ivanova NN, Mikhailova N, Ovchinnikova G, Hooper SD, Lykidis A, et al. GenePRIMP: a gene prediction improvement pipeline for prokaryotic genomes. Nat Methods. 2010;7:455-7.

42. Lowe TM, Eddy SR. tRNAscan-SE: a program for improved detection of transfer RNA genes in genomic sequence. Nucleic Acids Res. 1997;25:955-64.

43. Pruesse E, Quast C, Knittel K, Fuchs BM, Ludwig W, Peplies J, et al. SILVA: a comprehensive online resource for quality checked and aligned ribosomal RNA sequence data compatible with ARB. Nucleic Acids Res. 2007;35:7188-96.

44. INFERNAL. Inference of RNA alignments. [http://infernal.janelia.org]

45. Markowitz VM, Mavromatis K, Ivanova NN, Chen IM, Chu K, Kyrpides NC. IMG ER: a system for microbial genome annotation expert review and curation. Bioinformatics. 2009;25:2271-8.

46. De Meyer S, Fabiano E, Tian R, Van Berkum P, Seshadri R, Reddy T, et al. High-quality permanent draft genome sequence of the Parapiptadenia rigida-nodulating Cupriavidus sp. strain UYPR2.512. Stand Genomic Sci. 2015;10:13.

47. Tamura K, Peterson D, Peterson N, Stecher G, Nei M, Kumar S. MEGA5: Molecular Evolutionary Genetics Analysis using maximum likelihood, evolutionary distance, and maximum parsimony methods. Mol Biol Evol. 2011:28:2731-9.

48. Field D, Amaral-Zettler L, Cochrane G, Cole JR, Dawyndt P, Garrity GM, et al. The Genomic Standards Consortium. PLoS Biol. 2011;9:e1001088.

49. Woese CR, Kandler O, Wheelis ML. Towards a natural system of organisms: proposal for the domains Archaea, Bacteria, and Eucarya. Proc Natl Acad Sci U S A. 1990:87:4576-9.

50. Chen WX, Wang ET, Kuykendall LD. The Proteobacteria. New York: Springer; 2005.

51. Validation of publication of new names and new combinations previously effectively published outside the IJSEM. Int I Syst Evol Microbiol. 2005;55:2235-38

52. Garrity GM, Bell JA, Lilburn TE. Class II. Betaproteobacteria. In: Garrity GM, Brenner DJ, Krieg NR, Staley JT, editors. Bergey's manual of systematic bacteriology, vol. 2. 2nd ed. New York: Springer; 2005.

53. Garrity GM, Bell JA, Lilburn TE. Order 1. Burkholderiales. In: Garrity GM, Brenner DJ, Krieg NR, Staley JT, editors. Bergey's manual of systematic bacteriology, vol. 2. 2nd ed. New York: Springer; 2005.

54. Garrity GM, Bell JA, Lilburn TE. Family I. Burkholderiaceae. In: Garrity GM Brenner DJ, Krieg NR, Staley JT, editors. Bergey's manual of systematic bacteriology, vol. 2. 2nd ed. New York: Springer; 2005.

55. Palleroni NJ. Genus I. Burkholderia. In: Garrity GM, Brenner DJ, Krieg NR, Staley JT, editors. Bergey's manual of systematic bacteriology, vol. 2. 2nd ed. New York: Springer; 2005.

56. Ashburner M, Ball CA, Blake JA, Botstein D, Butler H, Cherry JM, et al. Gene ontology: tool for the unification of biology. The Gene Ontology Consortium. Nat Genet. 2000;25:25-9.

\section{Submit your next manuscript to BioMed Central and take full advantage of:}

- Convenient online submission

- Thorough peer review

- No space constraints or color figure charges

- Immediate publication on acceptance

- Inclusion in PubMed, CAS, Scopus and Google Scholar

- Research which is freely available for redistribution 